\title{
Language Proficiency in Children with Cleft Palate
}

\author{
María del Carmen Pamplona ${ }^{1,2^{*}}$ and Pablo Antonio Ysunza ${ }^{3}$ \\ ${ }^{1}$ Cleft Palate Clinic, Hospital Gea González, Mexico City, Mexico \\ ${ }^{2}$ Hablarte e Integrarte, $A C$, Mexico \\ ${ }^{3}$ Ian Jackson Craniofacial and Cleft Palate Clinic, Beaumont Health, Royal Oak, MI, USA
}

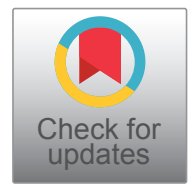

*Corresponding author: María del Carmen Pamplona, Cleft Palate Clinic, Hospital Gea González, Calz Tlalpan 4800, Col Sección XVI, CP 01420, Mexico City, Mexico, Tel: +525-555-850-784, E-mail: macamenpamplona@hotmail.com

\begin{abstract}
Background: Children with cleft palate (CCP) are at risk of speech disorders, which require a long intervention. Disorders of speech have been the most salient problems encountered by clinicians treating these children and have taken priority in research. Consequently, intervention has been focused on speech production, whereas assessment of language proficiency and the use of strategies for enhancing language development in this population have been overlooked.
\end{abstract}

Objective: To analyze the relationship between the development of cognitive-linguistic organization and the presence of compensatory articulation (CA) in CCP.

Materials and methods: A prospective study was carried out in which language proficiency of a group of CCP present with Compensatory Articulation were assessed and followed. When CCP with language disorder and CA were followed, different strategies were used in order to improve the language performance of these patients.

Results: CCP with CA demonstrated to have lower language performance than expected according to age norms. Later, when strategies for facilitating language comprehension and development were used during intervention CCP improved their level of abstraction and the use of complex discourse structures.

Discussion: Language proficiency seems to be affected in CCP with CA. A detailed evaluation of all aspects of cognitive and linguistic organization should be performed in these patients. Speech intervention should address not only the articulation process, but also specific aspects of language proficiency.

\section{Keywords}

Language, Cleft palate, Therapy

\section{Introduction}

Children with cleft palate (CCP) are at risk for a wide range of speech disorders that commonly includes hypernasality, nasal emission and/or articulation errors such as compensatory articulation (CA). Hypernasality is the excessive nasal resonance and can be noted during the production of consonants and even vowels; nasal emission is escape of air through the nose related to velopharyngeal insufficiency (VPI). Other cause for nasal emission can be an oronasal fistula that allows communication between the nasal and oral cavities. As these speech disorders are caused by an anatomical deficiency treatment has to be physical manipulation and cannot be treated in speech therapy [1]. In contrast, articulation errors should be treated in speech therapy. CA is also developed secondary to VPI and severely affects speech intelligibility. These articulation errors include dysfunction not only of the velopharyngeal sphincter but the entire vocal tract and require a prolonged period of speech intervention.

$\mathrm{CA}$ is established during early developmental stages. During phonological development, the baby develops vocal play and later on certain babbling sequences that serve as the building blocks for latter word production [2]. Babies with cleft palate have a disadvantage during this vocal development since the palate is not yet repaired at these stages and they have to engage in the vocal practice with a cleft palate. Differences in early vocal development can be identified in babies with unrepaired cleft palate as early as 6 months of age [3]. In many cases, having difficulty articulating and creating high intraoral pressure causes the generation of

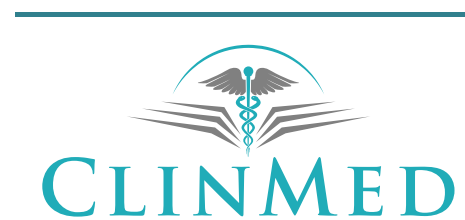

INTERNATIONAL LIBRARY

Citation: Pamplona MC, Ysunza PA (2018) Language Proficiency in Children with Cleft Palate. Int Arch Commun Disord 1:003.

Received: November 08, 2017; Accepted: March 03, 2018; Published: March 05, 2018

Copyright: (c) 2018 Pamplona MC, et al. This is an open-access article distributed under the terms of the Creative Commons Attribution License, which permits unrestricted use, distribution, and reproduction in any medium, provided the original author and source are credited. 
different rules for managing the sounds of speech. The oral production of plosive sounds such as $/ \mathrm{k} /, \mathrm{p} / \mathrm{or} / \mathrm{t} /$ might be attempted through a glottal stop substitution known as compensatory articulation. This disorder severely affects speech intelligibility and requires speech intervention.

Traditionally, CA has been considered a phonetic disorder since it may occur initially as a direct consequence of the cleft $[1,4,5]$. Recently, some authors have considered this impairment not just phonetic but rather a phonological disorder. Some reports describe that, over time, articulation errors can become incorporated into the child's developing rule system of articulation [6-8].

A phonetic disorder occurs when the movements of the articulators, such as lips, tongue, palate, or the shape of the resonating cavities are altered from normal or typical production. A compensatory behavior, such as glottal articulation would be considered phonetic when the child with VPI attempts to produce the sound with an alternative placement of the articulators and manner of articulation. This behavior occurs as a compensation for the inability to establish intraoral air pressure because of the cleft [6].

CA is secondary to VPI. However, although compensatory articulation is strongly associated to VPI, compensatory errors implicate a dysfunction not only of the velopharyngeal sphincter but also of the entire vocal tract. Because the glottal production reflects an obvious and productive compensation, the problem has been considered a phonetic error and hence, articulation has become the main focus of speech pathology intervention. However, a moderate percentage (approximately $33 \%$ ) of CCP with residual VPI after surgical repair of a palatal cleft exhibit CA [9]. In contrast, the relative majority (two thirds) of patients with cleft palate are able to produce most of the typical and adequate articulation patterns following the surgical repair of the cleft. No further articulation delays or deviations have been detected in this particular group [7].

The different clinical paths in CCP with and without compensatory articulation suggest that some other factors associated with phonological processing, other than just the inability to establish sufficient intraoral air pressure as well as inappropriate articulation placement, may be contributing to the development and persistence of these abnormal articulatory patterns [10].

In most cleft palate centers, surgical repairs of the secondary palate are performed between the ages of 6 and 18 months. This time window has been considered important because the first words start appearing between 12 and 14 months of age [11]. The initial appearance of words suggests that CCP are already establishing a phonologic and a semantic system, which is a set of linguistic rules that map the phonetic patterns of speech to the sound and syllable patterns of meaningful language.
A possible explanation for the emergence and persistence of compensatory articulation errors or patterns may be that a compensatory strategy for approximating sounds heard in the environment during the early stages of babbling becomes incorporated into the phonological rule system before the surgical repair of the cleft has been accomplished [12-14].

Following surgery, despite the fact that the child's ability for producing the plosive sounds or other speech patterns in a more typical manner has been adequately enhanced, the child persists in producing the compensatory articulation patterns because they have been integrated into the phonological rules. At this point in time, what once was a phonetic compensation becomes a phonological disorder $[6,15]$. As a productive rule, the articulatory production would not change until the rule is changed, despite that the mechanical and structural abilities to produce the sound adequately have been enhanced.

The presence of language disorders in CCP has received relatively little attention in the current related scientific literature [16]. However, a systematic review of the literature revealed that children and adults with cleft palate perform more poorly on cognitive tests than their age-matched peers [17]. They also found a high incidence of learning and language disabilities in CCP who had average intelligence. They found reports of a slightly lower average verbal IQ in CCP. Hardin-Jones and Chapman argued that these children need a full speech, language and cognitive assessment and broad-based intervention. The lack of attention toward these cognitive and linguistic areas could be explained because the speech characteristics associated with VPI are the most notorious problems encountered by clinicians and thus, these disorders have taken a high priority in research for many years [17].

Hoffman reported that children's speech sound production and perception errors are related not only to phonological knowledge, but also to higher organizational levels of language processing [10]. He also mentioned some research findings indicating that children, who have difficulty learning phonology, show similar difficulties for learning morphological, syntactic, and semantic regularities of language as well. It has also been recognized that there is a bidirectional relationship between phonology and language processing in children who are developing language [2].

Richman and Nopoulos studied the performance of CCP on language processing in areas like vocabulary, fluency, rapid verbal labeling, and sentence repetition [18]. They found that children with cleft palate have deficits in both receptive and expressive language areas. Other study also identified delays in vocabulary development in these children [19] and other authors found language delays in CCP as compared with noncleft children $[19,20]$. However, Collett, et al. reported 
no significant difference between cleft and non-cleft language development [21]. Then, in sum, the prevalence of language disorders in the cleft palate population is still a controverter subject since there is still not consistency concerning language development in children with cleft palate. But the statement that diagnosis and treatment of communication disorders in CCP should focus not only on speech and hearing but also on higher levels of language processing is beginning to be a topic of discussion.

\section{Materials and Methods}

For studying the relationship between $C A$ and the language system in CCP, a prospective study was carried out. In order to keep the study group as homogenous as possible, only children with total unilateral cleft lip and palate were selected. By the same token, all CCP underwent surgical repair of the palatal cleft before one year of age. Only CCP exhibiting residual VPI after palate repair were selected. A total of fifty-eight CCP with residual VPI were included in the study group. Further on CCP were divided into CCP with and without CA [22]. Twenty-nine CCP exhibited CA errors with different degrees of severity. Twenty-nine CCP demonstrated adequate articulation placement despite VPI (See Table 1). All CCP with or without CA were subjected to a language assessment. In the study, the language level was measured in a naturalistic condition such as storytelling using the SDS Model [23]. All interactions were video recorded for later transcription and analysis. The samples were analyzed by comparing the child's assigned levels to those expected at age level.

When CCP with CA and low linguistic performance were followed during intervention, the objective was to reinforce correct speech sounds while enhancing language processing [24]. For this purpose, some strategies described for language intervention such as modeling and/or expansions were used. In addition, the clinician used some strategies for improving expert-thinking processes, such as think-aloud during the speech and language pathology intervention. A complete clinical evaluation of speech, language and resonance was performed. The assessment also included a linguistic analysis during story telling/retelling and especial attention was focused on the linguistic discourse organization.

CCP were videotaped interacting with a trained speech pathologist during storytelling for $\mathbf{3 0}$ minutes

Table 1: Levels of language delay in both groups SDS model [23].

\begin{tabular}{|l|l|l|}
\hline Levels of delay & $\begin{array}{l}\text { Group 1 (active) } \\
\text { CCP + AC }\end{array}$ & $\begin{array}{l}\text { Group 2 } \\
\text { CCP without AC }\end{array}$ \\
\hline $\begin{array}{l}\text { 0 levels of delay within } \\
\text { normal limits }\end{array}$ & $0 \%$ & $73 \%$ \\
\hline $1-2$ levels of delay & $53 \%$ & $27 \%$ \\
\hline $3-4$ levels of delay & $47 \%$ & $0 \%$ \\
\hline P $>0.05$. & & \\
\hline
\end{tabular}

before and after the treatment in order to measure advances. All CCP received a speech pathology intervention aimed to stimulate language and correct compensatory articulation according to the principles of the Whole Language Model [25]. Intervention was aimed to reinforce correct speech sounds while enhancing cognitive-linguistic organization. The treatment goals were set depending on the levels of language development detected. Within these main principles of intervention, strategies described for language intervention such as modeling, expansions and/or cloze procedure were used [26]. As stated before, for this project the clinicians added metacognitive strategies, described for reading comprehension and for developing expert-thinking processes.

CCP were grouped according to chronological age, and linguistic and cognitive levels. Activities were planned according to the group's levels of performance. Reading and storytelling were the main context for intervention. Strategies for language and articulation were used before, during, and after the storybook reading. CCP were invited to reflect and discuss about the content of the book and were exposed to metacognitive strategies such as think-aloud [27]. During think-aloud strategy, the clinician verbalizes thoughts aloud while reading or talking, thus modeling the process of comprehension and what "experts" do before, during, and after reading a selection especially designed for using expert thinking processes.

The idea is to teach explicitly the use of the strategies. Oczkus developed a practical way to teach and think about the strategies using symbols for each one in order to help children to understand and remember [28]. The same methodology was used for enhancing language processing, and the use of the strategies. The following metacognitive strategies were explicitly taught to the children through think aloud:

\section{Making connections}

When we hear/read, we naturally make connections to our own experiences and knowledge. This knowledge helps us relate to the characters or setting and that improves our understanding of the topic helping us to build meaning. For example, "This reminds me of because ".

\section{Predicting}

Skill readers/language users use their connections to help them predict what will happen next. They also use what they know about the text structure for predicting what would happen next. For example, "I think will happen next because ".

\section{Inferring}

Block and Israel reported that readers that infer are the best readers. Inferring requires combining personal experience or prior knowledge with the content of the 
narration [27]. Inferring includes thinking in information not explicit in the context or text. An example could be "I can say that and it makes me think $"$.

\section{Questioning}

Questioning deepens comprehension. For comprehending, skill listeners/readers make questions, before, during and after the reading. These ensure the validity of future thoughts and guides comprehension as in: "I wonder why the character chose that option..."

\section{Summarizing}

Oczkus states that this skill includes a host of challenging tasks, including recalling important events or details, ordering points, and using synonyms or selected vocabulary [28]. Summarizing supports the language-learning process to restore information addressing the most important ideas and relationships between them. For example, "First ; then ; at the end

\section{Evaluating}

Good language users/readers get to be judges (author, character, or text). Evaluating involves determining importance and encourages reflection. For instance, "I agree/disagree because $"$.

\section{Results}

When assessing language performance in CCP with $\mathrm{CA}$, language level of the children with CA differed from children with repaired cleft palates, who did not show the compensatory articulation speech patterns. Differences were found in their overall development of language including the ability to process language and the use of semantic, syntactic, and discourse elements of language rules to express meaning and not just in speech production. CCP without compensatory articulation performed consistently with age norms [22]. In this study, the most severe delays were found when exploring the meaning expressed during storybook reading while looking at the illustrations. Specifically, delays were found when the distance between the material and language widens, and the focus must change from the concrete information of the illustrations to expressing abstract meaning such as inferring or evaluating [23]. In other words, the necessary skills for achieving the linguistic tasks described herein depend crucially on processes and representations from a variety of cognitive domains [29]. CCP with CA showed difficulties with both the event structures and the concomitant language. Many of these children could not interpret more than just the most familiar early events (i.e., bathing) from pictures. Similarly, they did not demonstrate elaborated knowledge of events structures in the discourse analysis, without temporal or causal sequences of actions. Without the development of elaborated and complex event structures, a context for learning the language of interpretations and inferences was not available [23].

\section{Discussion}

The finding that CCP with CA could not interpret more than just the most familiar events from pictures and they did not demonstrate elaborated knowledge of event structures, agrees with Coloma and colleagues results when studying language comprehension in a group of children with specific language impairment in comparison with children with typical development of similar ages [30]. The authors found significant differences in narrative comprehension between both groups of children. Other authors found similar results related to the difficulties children with language impairment present including finding and expressing main ideas [31], or elaborating questions and inferences [32].

From a holistic point of view, is also important to consider the assessment. Bavin and Bretherton mentioned that language assessments are sometimes limited to measure vocabulary level [33]. Our own clinical experience suggests that frequently, clinicians who assess language by measuring specific linguistic abilities establish these same abilities as their main goal for intervention. If this is the case, measuring grammatical skills for assessing language could imply that higher-order processing language skills may not have been included as one of the main goals during intervention.

Moreover, in cleft palate population, another important factor is the risk for otitis media and hearing loss and the potential impact in language development. Broen, et al. described the potential effects of otitis media on language development [19].

Other studies have found that the relationship between otitis media, hearing, and speech and language development is not conclusive [34,35]. Although at the present time the available information is still controversial, recurrent serous otitis media, which is, highly prevalent in CCP should be consider as a risk factor for affecting speech and language development in this population. Wallace and colleagues [36] studied the relationship between otitis media, language and the style of interaction of the caregivers. They also found that otitis media was not associated with the level of receptive language of CCP, but did showed expressive language development below the expected norms in specific situations such as play. The authors concluded that the communicative strategies used by the caregivers might counteract the additional risk factor that otitis media places on CCP. Thus, caregivers and clinicians attending CCP should receive information for stimulating language development with a nurturing style of interaction.

Considering CA as a phonological disorder has many implications for intervention. First, during the initial assessment, an analysis of phonological processes in addition to phonetic analysis should be performed. Second, it should be pointed out that some researchers have taken a holistic approach to the study of language, 
where the "whole" is not merely the sum of its parts. The phonological system is integrated with the rest of the language system $[7,10]$. The components of language (phonology, grammar and/or vocabulary) have no meaning when they are isolated from each other $[26,37]$. Hence, the Whole Language Model (WLM) postulates that for clinical reasons language should not be separated into its different components [25]. Following this statement, it has been suggested that the speech pathology intervention for CCP with CA should address not only articulation but also all linguistic components such as pragmatics, vocabulary, and the use of abstractions such as inferences or evaluations. It is now recognized that the emergence of critical cognitive systems, such as those used for perception, storage, recognition, and retrieval of information which shapes and times the early language acquisition process is not a separate, self-encapsulated module that develops independently of other systems [38].

As mentioned before, language development has not been considered as a priority in CCP. Most of the emphasis has been aimed to enhance speech development and treat speech and sound disorders. Thus, the use of strategies for enhancing language development in this population has been somehow overlooked [24].

Language and speech cannot be considered separate entities, as mentioned herein they are deeply intertwined. Many authors have now supported this statement stating that children who showed language delays also displayed delays in phonological development $[39,40]$. Moreover, the study presented above, CCP with AC presented language issues [22]. The implications of these findings seem to support that for a successful outcome, it is essential to address articulation as well as language. The Whole Language Model seems to be a good option for addressing speech and language with a holistic approach [37] where speech and phonology always are addressed within a linguistic context [26].

In addition, in developing countries CCP present several other risk factors. Some studies have reported that children from families with low socio-economic status have poor language skills in a variety of linguistic domains including vocabulary, grammar, narrative development, phonological development and speed of processing [41]. For instance, the proportion of children living in poverty whose language development reflects influence of socioeconomic status is likely to be greater than $22 \%$. Mothers with less education often talk less to their children, make use of a smaller vocabulary and they use less complex and varied syntactic structures. These mothers use language in a way that is less nurturing and supportive for language development [41]. All these situations contribute to the vulnerability of the population of CCP in developing countries since they are at a higher risk for presenting with language disorders in addition to the more obvious speech deficits. As a con- sequence, they require a more complete and effective speech pathology intervention that addresses all linguistic areas and skills. Treating only articulation aspects in this group of patients is not enough. It is more adequate to consider higher levels of linguistic organization such as abstract thought. In this context, phonological information can be integrated with all linguistic areas in all situations with communicative purposes $[26,42]$. The correct production of speech sounds is no longer the only goal but to guide the children to become effective communicators and language users.

For addressing language many strategies can be used. For comprehending and organizing a narration or oral discourse effective communicators use different strategies. Many of them are developed naturally. However, it is now recommended that they should be explicitly taught during stimulation or intervention [24]. It has been described that expert readers use the strategies described herein for making meaning from text [27]. That is why it is paramount to include this content during intervention. Metacognition or being metacognitive implies having awareness and being capable of regulation. Two categories of metacognition can be identified: Knowledge about cognition and regulation of cognition.

Metacognition researchers have highlighted the importance of supporting student's planning, monitoring, and self-regulating strategies through interventions to enhance learning. Within the past 20 years, educators have adopted metacognitive strategies in instructional design for students of all ages with positive results [28].

CCP who learn how to use metacognitive strategies improve their language levels by using more complex discourse structures and higher order language processing [24]. They are also able to improve their level of abstraction [23]. When the metacognitive strategies are used during intervention, the linguistic emissions of CCP and compensatory articulation usually showed a higher level of complexity and abstraction. The use of the strategies facilitate the use of inferences, evaluations, connections, and help children to analyze the story and other real situations in more complex ways. Through the use of metacognitive strategies, children become more able to incorporate details in their narrations and they can take different perspectives when analyzing the plot of a story. Thus, it may be concluded that metacognitive strategies can be useful for enhancing higher-order language for narration, interpretation, evaluation and organization, and this could be reflected in both, written and oral language [24]. This conclusion agrees with The Local Homology Model described by Bates, et al., which argues that language is an interactive system that depends crucially on processes and representations from a variety of cognitive domains [29].

It has also being described that children with language delays show weaknesses especially in the abili- 
ties for using complex, higher-order language for narration, definition, explanation, description, exposition and even reading [43].

Considering the issues addressed previously, intervention could be determinant for stimulating speech and language development in the cleft palate population. It is extremely important not to neglect aspects of language development in children with cleft palate. Furthermore, it seems that the use of metacognitive strategies may be useful for enhancing linguistic processing and discourse organization.

It has been documented that children with language disorders represent a special challenge for the educators. That is, educators have a positive effect on children's language acquisition [44]. The quality and quantity of childcare have been shown to have short-term as well as long-term positive effects on cognitive and non - cognitive outcomes in children [45].

High quality childcare with high quality curriculum-based instruction embed in positive and responsive interactions, which are necessary for improving academic outcome, including language development, especially in children at a social and economic disadvantage [46]. Another study demonstrated that children of mothers with low levels of education who received formal childcare, obtained higher school readiness in comparison with those who were cared by their parents [47]. Thus, in developing countries with limited resources where it is practically impossible for the public education system to provide adequate assessment and treatment for cleft palate patients, speech and language pathologists have a special responsibility for providing an intervention that can address not only speech aspects but that can actually enhance cognitive and higher-order processing of language. In other words, the main goal should be not only to correct speech sound disorders but also to provide the CCP with the necessary abilities for becoming effective and efficient oral communicators.

\section{References}

1. Golding Kushner KJ (2001) Therapy techniques for cleft palate speech and related disorders. ( $1^{\text {st }}$ edn), Singular, San Diego, CA, USA.

2. Stoel Gammon C (2011) Relationships between lexical and phonological development in young children. J Child Lang 38: 1-34.

3. Peterson Falzone S, Trost Cardamone J, Karnell M, Hardin Jones M (2006) The clinician's guide to treating cleft palate speech. Mosby

4. McWilliams BJ, Musgrave RH (1971) Diagnosis of speech problems in patients with cleft palate. International Journal of Language \& Communication Disorders 6: 26-32.

5. Van Demark DR, Morris HL, Vandehaar C (1979) Patterns of articulation abilities in speakers with cleft palate. Cleft Palate J 16: 230-239.

6. Chapman KL (1993) Phonologic processes in children with cleft palate. The Cleft Palate-Craniofacial Journal 30: 64-72.
7. Pamplona MC, Ysunza A, Espinosa J (1999) A comparative trial of two modalities of speech intervention for compensatory articulation in cleft palate children, phonologic approach versus articulatory approach. Int J Pediatr Otorhinolaryngol 49: 21-26.

8. Powers GR, Dunn C, Erickson CB (1990) Speech analyses of four children with repaired cleft palates. J Speech Hear Disord 55: 542-549.

9. Pamplona MC, Ysunza A, Guerrero M, Mayer I, García Velasco M (1995) Estudio del efecto de la corrección quirúrgica de la insuficiencia velofaríngea sobre la integración de la articulación al lenguaje espontáneo. An Otorrinolaringol Mex 40: 36-40.

10. Hoffman PR (1992) Synergistic development of phonetic skill. Language, Speech, and Hearing Services in Schools 23: $254-260$.

11. Ysunza A, Pamplona MC, Mendoza M, García Velasco M, Aguilar MP, et al. (1998) Speech outcome and maxillary growth in patients with unilateral complete cleft lip/palate operated on at 6 versus 12 months of age. Plast Reconstr Surg 102: 675-679.

12. Ha S (2015) Effectiveness of a parent-implemented intervention program for young children with cleft palate. Int $\mathrm{J}$ Pediatr Otorhinolaryngol 79: 707-715.

13. Scherer NJ, Boyce S, Martin G (2013) Pre-linguistic children with cleft palate: Growth of gesture, vocalization, and word use. Int J Speech Lang Pathol 15: 586-592.

14. Scherer NJ, Williams AL, Proctor Williams K (2008) Early and later vocalization skills in children with and without cleft palate. Int J Pediatr Otorhinolaryngol 72: 827-840.

15. Hardin Jones M, Chapman KL (2008) The impact of early intervention on speech and lexical development for toddlers with cleft palate: A retrospective look at outcome. Lang Speech Hear Serv Sch 39: 89-96.

16. Young SE, Purcell AA, Ballard KJ (2010) Expressive language skills in chinese singaporean preschoolers with nonsyndromic cleft lip and/or palate. International Journal of Pediatric Otorhinolaryngology 74: 456-464.

17. Hardin Jones M, Chapman K (2011) Cognitive and language issues associated with cleft lip and palate. Semin Speech Lang 32: 127-140.

18. Richman L, Nopoulos P (2008) Neuropsychological and neuroimaging aspects of clefting. In: J Losee, R Kirschner, Comprehensive cleft care. McGraw-Hill Education, New York.

19. Broen PA, Devers MC, Doyle SS, Prouty JM, Moller KT (1998) Acquisition of linguistic and cognitive skills by children with cleft palate. J Speech Lang Hear Res 41: 676687.

20. Scherer NJ, D’Antonio LL (1995) Parent questionnaire for screening early language development in children with cleft palate. Cleft Palate Craniofac J 32: 7-13.

21. Collett BR, Leroux B, Speltz ML (2010) Language and early reading among children with orofacial clefts. Cleft Palate Craniofac J 47: 284-292.

22. Pamplona MC, Ysunza A, González M, Ramírez E, Patiño C (2000) Linguistic development in cleft palate patients with and without compensatory articulation disorder. Int J Pediatr Otorhinolaryngol 54: 81-91.

23. Norris JA, Hoffman PR (1993) Whole Language Intervention for School-age Children. Singular Publishing Group, Albany, United States. 
24. Pamplona MC, Silis SC, Ysunza PA, Morales S (2015) Metacognitive strategies for enhancing language development in children with cleft palate. European Journal of Plastic Surgery 1-8.

25. Norris JA, Damico JS (1990) Whole language in theory and practice: Implications for language intervention. Lang Speech Hear Serv Sch 21: 212-220.

26. Norris JA, Hoffman PR (1990) Language intervention within naturalistic environments. Lang Speech Hear Serv Sch 21: 72-84.

27. Block CC, Israel SE (2004) The ABCs of performing highly effective think-alouds. The Reading Teacher 58: 154-167.

28. Oczku L (2009) Interactive think-aloud lessons: 25 surefire ways to engage students and improve comprehension. Teaching Resources.

29. Bates E, Bretherton I, Snyder LS (1991) From first words to grammar: Individual differences and dissociable mechanisms. Cambridge University Press, 20.

30. Coloma CJ, Maggiolo M, Pavez MM (2013) Comprensión de narraciones orales en niños con Trastorno Específico del Lenguaje. Actualidades en Psicología 27: 129-140.

31. Bishop D, Donlan C (2005) The role of syntax in encoding and recall of pictorial narratives: Evidence from Specific Language Impairment. British Journal of Developmental Psychology 23: 25-46.

32. Norbury C, Bishop D (2002) Inferential processing and story recall in children with communication problems: A comparison of specific language impairment, pragmatic language impairment and high-functioning autism. Int $\mathrm{J}$ Lang Commun Disord 37: 227-251.

33. Bavin E, Bretherton L (2013) The early language in victoria study: Late talkers, predictors, and outcomes. In: L Rescorla, PS Dale, Late Talkers: Language Development, Interventions, and Outcomes. Paul $\mathrm{H}$ Brookes Publishing Company, USA, 3-22.

34. Casby MW (2001) Otitis media and language development: A meta-analysis. American Journal of Speech-Language Pathology 10: 65-80.

35. Scherer NJ, Kaiser AP (2007) Early intervention for children with cleft palate. Infants \& Young Children 20: 355-366.

36. Wallace IF, Gravel JS, Schwartz RG, Ruben RJ (1996) Otitis media, communication style of primary caregivers and language skills of 2 year olds: A preliminary report. J Dev Behav Pediatr 17: 27-35.

37. Ling $P$ (2012) The "Whole Language" theory and its application to the teaching of english reading. English Language Teaching 5: 147-155.

38. Thal D, Marchman V, Tomblin J (2013) Late-talking toddlers: Characterization and prediction of continued delay. In: L Rescorla, PS Dale, Late Talkers: Language Development, Interventions, and Outcomes. Paul H Brookes Publishing Company, USA, 169-203.

39. MacRoy Higgins M, Schwartz RG (2013) Phonology and the Lexicon in Late Talkers. In: L Rescorla, PS Dale, Late Talkers: Language Development, Interventions and Outcomes. Paul H Brookes Publishing Company, USA.

40. Williams AL, Elbert M (2003) A prospective longitudinal study of phonological development in late talkers. Lang Speech Hear Serv Sch 34: 138-153.

41. Hoff E (2003) The Specificity of Environmental Influence: Socioeconomic status affects early vocabulary development via maternal speech. Child Development 74: 1368-1378.

42. Pamplona MC, Ysunza A, Patiño C, Ramírez E, Drucker M, et al. (2005) Speech summer camp for treating articulation disorders in cleft palate patients. Int $\mathrm{J}$ Pediatr Otorhinolaryngol 69: 351-359.

43. Chapman KL (2011) The relationship between early reading skills and speech and language performance in young children with cleft lip and palate. Cleft Palate Craniofac $\mathrm{J}$ 48: 301-311.

44. Vasilyeva M, Waterfall $\mathrm{H}$ (2011) Variability in language development: Relation to socioeconomic status and environmental input. Handbook of Early Literacy Research 3: 37.

45. Hall J, Sylva K, Melhuish E, Sammons P, Siraj Blatchford I, et al. (2009) The role of pre-school quality in promoting resilience in the cognitive development of young children. Oxford Review of Education 35: 331-352.

46. Burchinal M, Vandergrift N, Pianta R, Mashburn A (2010) Threshold analysis of association between child care quality and child outcomes for low-income children in pre-kindergarten programs. Early Childhood Research Quarterly 25: 166-176.

47. Bleses D, Vach W (2013) Danish Late Talkers: A first portrait. In: L Rescorla, PS Dale, Late Talkers: Language Development, Interventions and Outcomes. Paul H Brookes Publishing Company, USA. 